\title{
Comercialização de Plantas Medicinais no Município de Arapiraca-AL
}

LIMA, I.E.O.'; NASCIMENTO, L.A.M.'; SILVA, M.S. ${ }^{*}$.

Universidade Estadual de Alagoas - UNEAL/Campus I. Departamento de Biologia. Rua Governador Luiz Cavalcante, S/N, Arapiraca - AL, 57312-000, Brasil. *Autor para correspondência: prof.silene.uneal@gmail.com

\begin{abstract}
RESUMO: O comércio de plantas medicinais em feiras livres faz parte da cultura de muitas cidades da região Nordeste do Brasil. Objetivou-se com esta pesquisa verificar a existência de padrões de comercialização de plantas medicinais nas feiras livres do município de Arapiraca-AL. A metodologia incluiu a realização de entrevistas semiestruturadas, aplicadas a vendedores de plantas medicinais, sendo estas gravadas em áudio após assinatura do Termo de Consentimento Livre e Esclarecido, as técnicas da observação direta, "bola de neve" e lista livre. Os informantes indicaram 42 plantas medicinais, tendo Fabaceae com maior destaque em número de espécies. Do total de espécies identificadas, a maior parte é nativa ( $82 \%)$ e o hábito predominante é o arbóreo. Este estudo revelou que a produção e comercialização de plantas medicinais possuem um padrão local, com as plantas adquiridas através de terceiros, não havendo um padrão mínimo de qualidade, sendo necessária a implantação de políticas públicas voltadas a capacitação destes profissionais, agregando valor ao saber popular sobre plantas medicinais.
\end{abstract}

Palavras-chave: Plantas medicinais. Padrão de comercialização. Etnobotânica

\begin{abstract}
Medicinal Plants commercialization in the city of Arapiraca-AL. The marketing of medicinal plants in street fairs is part of the culture of many cities in the Northeast of Brazil. The aim of this study was to identify the marketing patterns of medicinal plants in Arapiraca-AL city. The methodologies involved semi-structured interviews, givento the merchants of medicinal plants, $t$ after a Free and Clear Consent Form, by which the survey participants were aware of the risks and benefits of it and can stop it if necessary to judge, the interviews were recorded. Snowball and free list techniques were also used. The informants indicated 42 species; Fabaceae had the highest number of species. From the total of identified medicinal plants, $80 \%$ were native and the predominant habitat was arboreous. This study revealed that the production and marketing of medicinal plants has a local pattern, with the plants being acquired through outsourcing, and there is no minimum quality standard, requiring the implementation of public policies for the training of these professionals, adding value to the common knowledge of medicinal plants.
\end{abstract}

Key words: Medicinal plants. Marketing standards.Ethnobotany

\section{INTRODUÇÃO}

De acordo com a Organização Mundial da Saúde (OMS, 2008), plantas medicinais são todas aquelas que contêm em um ou mais de seus órgãos substâncias que podem ser utilizadas com propósitos terapêuticos ou que sejam precursoras de semissíntese químico-farmacêutica. Já que $80 \%$ da população mundial utilizam estas plantas ou preparações destas no que se refere à atenção primária de saúde, destacando-se a participação dos países em desenvolvimento, como o Brasil, detentores de $67 \%$ das espécies vegetais do mundo (Brasil, 2006a), o estudo de suas formas de comercialização e uso popular reveste-se de importância no que se refere à conservação das espécies e do saber popular a elas associado.

As plantas medicinais são produtos de venda livre, sendo necessário o aconselhamento dos profissionais que detêm o conhecimento científico sobre o uso farmacológico de fitoterápicos (Oliveira Neto et al., 2013), como farmacêuticos e outros profissionais da área da saúde. A Política Nacional de Práticas Integrativas e Complementares do SUS (Brasil, 2006a) possibilita a fusão do conhecimento técnico-científico destes profissionais com o saber popular sobre plantas medicinais, gerado e mantido por grupamentos culturais que ainda 
convivem com a natureza, observando-a de perto no seu dia-a-dia, e explorando suas potencialidades (elizabetski, 1997), como os raizeiros e vendedores de plantas medicinais, e especialistas locais (rezadores, curandeiros) já identificados em estudos realizados em comunidades tradicionais da cidade de Arapiraca-AL (Araújo \& Silva, 2012; Oliveira \& Pereira, 2012).

São necessários parâmetros para a segurança do uso de plantas medicinais, como, por exemplo, na secagem das plantas, que deverá ser feita ao abrigo de luz, e no armazenamento, que deverá ser em local seco e ventilado (Mengues et al., 2001). Conhecendo a demanda e os padrões de qualidade previamente estabelecidos, o produtor pode tomar decisões sobre o que, como, quanto e quando produzir. Entretanto, ainda há carência de informações e tecnologias nessa cadeia, o que desfavorece a obtenção de um produto final nestes padrões (Souza et al., 2012).

Aexistência de um padrão de comercialização das plantas medicinais é importante, visto que esta comercialização continua sendo praticada devido à eficácia e também pelo uso de produtos naturais para o tratamento de enfermidades. Diante desse cenário, é fundamental focar a atenção na qualidade das plantas e derivados que são produzidos, comercializados e utilizados pela população (Carvalho et al., 2010).

Padrão é o conjunto de atributos de qualidade e de identidade, pré-estabelecidos, que condicionam a produção e comercialização de produtos (Agrolink, 2015). De acordo com Barros (2007), a comercialização é um processo social que envolve interações entre agentes econômicos através de instituições apropriadas. Uma importante instituição no sistema de comercialização é o mercado. Este deve ser entendido como o "local" em que operam as forças da oferta e demanda, através de vendedores e compradores.

Atualmente, tanto nas regiões mais pobres do país como nas grandes cidades brasileiras, as plantas medicinais são comercializadas em feiras livres, mercados populares e encontradas em quintais residenciais (Tresvenzol et al., 2006).

Segundo Silva et al. (2001) este comércio abrange várias espécies e inclui partes, produtos e subprodutos de plantas, sendo a grande maioria, comercializadas somente pelo nome popular. $\mathrm{O}$ comércio local não é controlado, inclui plantas medicinais muitas vezes não estudadas ou que ainda não tiveram seus princípios ativos identificados para validá-las como medicamentos ou aproveitálas adequada e economicamente. As plantas são utilizadas por uma variedade de usuários localizados em qualquer lugar do país.

Cerca de $75 \%$ da população mundial utilizam as plantas medicinais no tratamento de doenças, devido às características desejáveis associadas ao uso, como eficácia, baixo custo, reprodutibilidade e constância de qualidade (Carvalho et al., 2010). Devido à grande demanda por produtos a base de plantas medicinais, faz-se necessário investigar como esses produtos estão sendo oferecidos ao consumidor, de acordo com a legislação específica e critérios estabelecidos cientificamente. Estudos diversos têm confirmado o efeito terapêutico de muitas espécies de plantas (Fennell et al., 2004; Melo et al., 2007), mas também há necessidade urgente da vigilância de fitoterápicos, devido à falta de padronização e qualidade.

De acordo com Melo et al. (2004) embora existam parâmetros específicos para a produção e comércio de fitoterápicos, a fraude e a má qualidade têm ocorrido e preocupado profissionais da área de saúde e a comunidade científica. A ausência de qualidade, a adulteração e a incorreta utilização, interferem na eficácia e até mesmo na segurança dos usuários de plantas medicinais. $\mathrm{O}$ controle de qualidade da produção e da comercialização de drogas vegetais no Brasil é realizado com base em legislação específica. As diretrizes da Política Nacional de Plantas Medicinais e Fitoterápicos (Brasil, 2006b) destacam a necessidade de regulamentar o cultivo, o manejo sustentável, a produção, a distribuição e o uso de plantas medicinais e fitoterápicos. Já a Agência Nacional de Vigilância Sanitária (ANVISA) através da RDC n¹0 de 09 de março de 2010, destaca a necessidade de notificação de drogas vegetais junto àquela agência, considerando a necessidade de contribuir para a construção do marco regulatório para produção, distribuição e uso de plantas medicinais, particularmente sob a forma de drogas vegetais.

$\mathrm{Na}$ região Nordeste do Brasil é comum observar-se o comércio de plantas medicinais nas feiras livres e mercados, através dos quais a população tem acesso a diferentes espécies de plantas medicinais, bem como a formulações caseiras preparadas com as mesmas, como o observado nas feiras livres do município de Arapiraca-AL.

As feiras livres de Arapiraca, cuja origem remonta ao ano de 1884, ainda são vistas como fatores de integração socioeconômica do agreste alagoano, que abrange as cidades circunvizinhas. $\mathrm{Na}$ feira livre de Arapiraca, o comércio de mercadorias é bastante variado, onde se encontra praticamente de tudo, inclusive plantas medicinais (Arapiraca, 2016).

Baseando-se nestes pressupostos, esta pesquisa teve como objetivo geral a verificação da existência de padrão de produção, comercialização, e uso de plantas medicinais no município de Arapiraca -AL, visando identificar botanicamente as

Rev. Bras. PI. Med., Campinas, v.18, n.2, p.462-472, 2016. 
espécies e as partes das plantas comercializadas, verificar como foram adquiridos os conhecimentos sobre as referidas plantas, conhecer o modo de uso e para qual enfermidade são utilizadas, verificar os produtos produzidos a partir das plantas medicinais e comparar os dados obtidos com os registrados na Farmacopeia Brasileira (ANVISA, 2010).

\section{METODOLOGIA}

A pesquisa foi realizada no Município de Arapiraca-AL, entre os meses de dezembro de 2014 e março de 2015, por meio de entrevistas semiestruturadas aos raizeiros e comerciantes de plantas medicinais. Arapiraca possui aproximadamente 214.006 habitantes, distribuídos em uma área territorial de $356,179 \mathrm{~km}^{2}$ e com uma densidade demográfica de 600,84 habitantes por $\mathrm{km}^{2}$, é o segundo maior município de Alagoas, destaca-se como importante centro comercial da região agreste atendendo não só a esta região, mas ao Sertão e ao Baixo São Francisco (IBGE, 2010).

Existem onze feiras cadastradas pela prefeitura da cidade de Arapiraca (Tabela 1). As feiras estão localizadas em pontos estratégicos da cidade e funcionam nos seguintes bairros: Centro, Baixão, Primavera, Brasília, Itapoã, Senador Teotônio Vilela, Jardim Esperança, Jardim Tropical

TABELA 1. Distribuição de feiras livres no município de Arapiraca - AL. Fonte: Prefeitura de Arapiraca(2016)

\begin{tabular}{|c|c|c|c|}
\hline \multirow{2}{*}{$\begin{array}{r}\text { Feira } \\
\text { Tradicional }\end{array}$} & Bairro & Dia da Semana & Ruas Ocupadas \\
\hline & Centro e Baixão & Segunda-Feira & $\begin{array}{l}\text { Rua Mauricio Pereira } \\
\text { Rua Teodorico costa } \\
\text { Rua do Sol } \\
\text { Rua Pedro leão } \\
\text { Rua Tiradentes } \\
\text { Rua Miguel Correia Amorim } \\
\text { Rua Padre Cícero } \\
\text { Rua José Lopes da Silva } \\
\text { Rua Manoel Ângelo Tavares. }\end{array}$ \\
\hline Fumageira & Primavera & Domingo & $\begin{array}{l}\text { Rua Engenheiro Camilo } \\
\text { Rua } 31 \text { de março } \\
\text { Rua Sargento Benevides } \\
\text { Rua Olinda } \\
\text { Rua Braz vieira. }\end{array}$ \\
\hline Baixão & Baixão & Domingo & $\begin{array}{l}\text { Av. Miguel Correia Amorim } \\
\text { (Antiga Avenida Norte) }\end{array}$ \\
\hline Brasília & Brasília & Quinta-Feira & $\begin{array}{l}\text { Rua Senador Rui Palmeira } \\
\text { Rua Firmino Leite } \\
\text { Rua Domingos Barbosa. }\end{array}$ \\
\hline Itapoã & Itapoã & Sábado & $\begin{array}{l}\text { Rua Nossa Sra da Salete } \\
\text { Rua Nossa Sra do Ó }\end{array}$ \\
\hline Rua São Paulo & Senador Teotônio Vilela & Domingo & $\begin{array}{l}\text { Rua São Paulo } \\
\text { Rua Nossa Sra. das Dores } \\
\text { Rua Samaritana } \\
\text { Rua São Geraldo }\end{array}$ \\
\hline Jardim Esperança & Jardim Esperança & Domingo & Praça Maria das Dores \\
\hline Jardim Tropical & Jardim Tropical & Domingo & Rua Adão Henrique \\
\hline Canafístula & Canafístula & Domingo & Rua Lúcio Vital \\
\hline Feira Fixa da Fumageira & Primavera & Domingo a Domingo & Praça Eloísio Lopes \\
\hline Feira do Atacado & Centro & Quartas e Quintas & Estacionamento do Mercado \\
\hline
\end{tabular}


e Canafístula. Há duas casas de ervas, que se localizam no bairro Baixão e no Centro. Um raizeiro ambulante também foi encontrado no centro da cidade.

\section{Amostra}

A amostra foi não probabilística e intencional. Para a seleção da amostra foi utilizado como critério de inclusão, ser comerciante de plantas medicinais em feiras livres e no comércio do município de Arapiraca-AL e como critério de exclusão, indivíduos menores de idade.

Utilizando-se a observação direta, foram realizadas visitas periódicas as onze feiras cadastradas pela prefeitura municipal de Arapiraca-AL, buscando-se identificar os comerciantes de plantas medicinais, denominados pela comunidade de raizeiros.

Para a identificação dos informantes foi utilizada a técnica da bola de neve que, segundo Bailey (1994), é uma forma de amostra não probabilística utilizada em pesquisas sociais na qual os participantes iniciais de um estudo indicam outros participantes que, por sua vez, indicam outros participantes e assim sucessivamente, até que o objetivo esperado seja alcançado. Assim, na feira denominada de Tradicional, localizamos a primeira raizeira, mas esta também comercializava plantas medicinais nas feiras do Centro, e dos bairros Brasília, Itapoã, Senador Teotônio Vilela e Baixão. Esta foi entrevistada e deu como referência outra raizeira, que localizamos na feira da Fumageira, comercializando plantas em um quiosque. Por este método identificamos duas informantes, das quais uma pelo seu vasto conhecimento sobre plantas medicinais foi classificada como informante-chave. Pelo pequeno tamanho amostral encontrado, decidimos realizar um cruzamento de informações de mais de uma fonte. Assim utilizou-se o cruzamento dos dados das raizeiras com o dos demais comerciantes das feiras e foi perguntado a estes comerciantes se eles conheciam pessoas que comercializavam plantas medicinais nas feiras livres ou em outro local da cidade. Dessa forma, chegamos a mais 3 informantes, porém estes não foram encontrados vendendo em de feiras livres, mas sendo dois comerciantes de plantas medicinais de casa de ervas, uma localizada no bairro Baixão, próximo à feira Tradicional, e outra no Centro da cidade, onde também foi identificado um vendedor ambulante. Assim, nossa amostra foi composta por cinco sujeitos.

Dentre as feiras livres cadastradas pela prefeitura, apenas duas foram selecionadas: a feira livre do bairro Baixão e a feira livre do bairro Primavera, como mostra a figura 1. Isso deveuse a facilidade de acesso, mas principalmente pelo fato de em cinco feiras livres não haver sido identificado nenhum comerciante de plantas medicinais e as duas informantes identificadas comercializavam plantas medicinais em seis feiras livres. Maia \& Coelho (1997) afirmam que isso ocorre como "ampliação das possibilidades dos feirantes maximizarem suas vendas e satisfazerem públicos diferenciados".

\section{Recrutamento dos Sujeitos}

O recrutamento dos participantes da pesquisa foi de acordo com os critérios de inclusão pré-estabelecidos e em função dos objetivos da pesquisa. Foi adotado o critério de heterogeneidade dos participantes-chave da

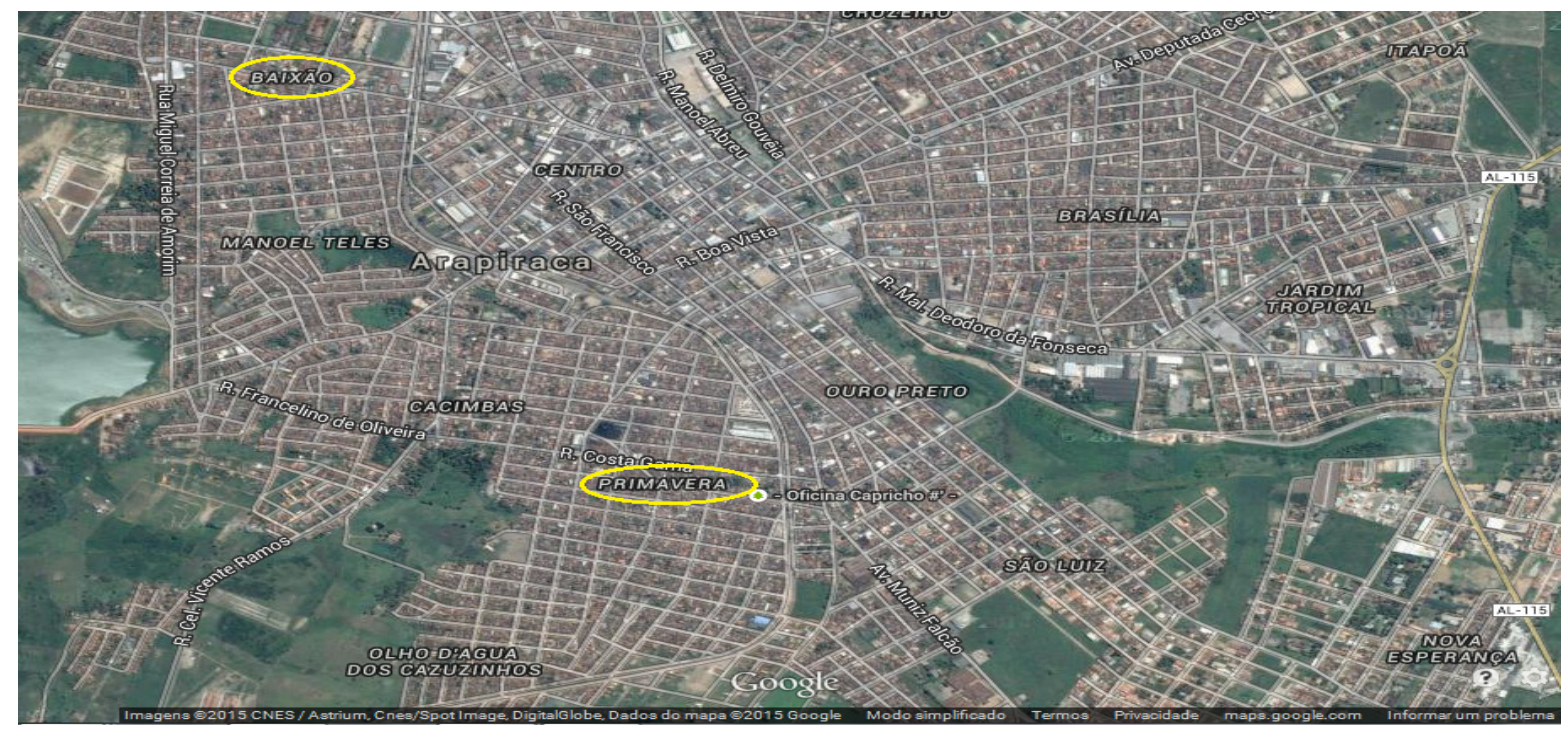

FIGURA 1. Bairros do Município de Arapiraca-AL, destacando-se os bairros onde estão localizadas as feiras livres selecionadas para a pesquisa. Fonte: Google Mapas 
pesquisa, que segundo Maxwell (2005) o referido método visa o máximo alcance da pesquisa na medida em que vários tipos de participantes poderão com ela se identificar.

A aceitação em participar da pesquisa se deu por meio da assinatura do Termo de Consentimento Livre e Esclarecido (TCLE), de acordo com a Resolução No 466 de 12 de Dezembro de 2012 do Conselho Nacional de Saúde (Brasil, 2013).

As entrevistas foram realizadas e gravadas em forma de áudio, e foram respondidas nos próprios locais de trabalho dos pesquisados, tanto nas feiras livres quanto na rua e nas casas de ervas. Este estudo foi aprovado pelo Comitê de Ética da Fundação Universitária de Ciências da Saúde/ Escola de Ciências Médicas - UNCISAL, com o parecer $\mathrm{n}^{\circ}$ 1.044.469.

\section{Técnica da Lista Livre}

Foi utilizado o método de listagem livre (Albuquerque et al., 2010) através do qual cada informante listou individualmente as espécies utilizadas para fins medicinais. Ainda segundo os autores, a lista livre é uma técnica muito comum para extrair informações nas ciências sociais, geralmente utilizada para identificar domínios culturais em uma comunidade estudada, na qual os informantes listam as espécies medicinais que conhecem e/ou usam. Essa técnica também é importante para identificar na comunidade especialistas locais em um determinado domínio cultural.

\section{Identificação Botânica das Espécies}

Devido ao estado de conservação das amostras das plantas encontradas durante a pesquisa, tornou-se impraticável a produção de exsicatas das mesmas para posterior identificação das espécies. A identificação botânica das plantas citadas durante a entrevista foi baseada em Oliveira \& Pereira (2012), que realizaram um levantamento etnobotânico em área próxima à região estudada e que ao obter as plantas durante seu estudo, as separaram e as utilizaram para a herborização, sendo preparadas exsicatas das espécies que foram depositadas ao Herbário MAC do Instituto do Meio Ambiente - IMA de Alagoas. Algumas das plantas foram identificadas através da literatura (Lorenzi \& Souza, 2007; Lorenzi 2006; Lorenzi \& Matos, 2008).

\section{Análise de Dados}

Para a análise dos dados coletados, organizou-se um banco de dados, utilizando o programa Microsoft Office Excel囚 2007 para fazer a frequência relativa, distribuindo em forma de porcentagens, em tabelas e figuras.

\section{RESULTADOS E DISCUSSÃO}

\section{Caracterização dos informantes}

Os raizeiros e comerciantes de plantas medicinais pertenciam na sua maioria ao gênero feminino $(n=3)$. A faixa etária entre as mulheres variou de 25 a 65 anos e entre os homens, variou de 35 a 75 anos. A maior parte possui renda mensal baixa, os quais dependem da comercialização dessas plantas para complementar suas rendas. Quanto à origem do conhecimento sobre plantas medicinais, afirmaram tê-lo adquirido pela vivência com os pais, que utilizavam em uso próprio ou para curar outras pessoas, porém, alguns disseram que mesmo assim, consultam livros sobre o assunto. Araújo et al.,(2009) observou forma de transmissão semelhante entre os raizeiros que comercializavam plantas medicinais na cidade de Maceió-AL.

Lós (2011) também realizou um estudo etnobotânico nas feiras livres do município de Arapiraca, identificando 21 informantes, vendedores de plantas medicinais em cinco feiras, das nove cadastradas na época. Em nosso trabalho identificamos apenas duas raizeiras em seis feiras, dois vendedores de casa de ervas e um vendedor ambulante. Baseando-se nestes dados, observa-se um forte declínio no número de comerciantes de plantas medicinais nas feiras livres de Arapiraca. Esta diminuição, segundo as informantes raizeiras, é atribuída a fatores tais como os gastos adicionais necessários para manter as bancas nas feiras, pois além da aquisição dos produtos, elas têm que pagar - aluguel da banca e uma taxa extra à prefeitura, tornando o lucro total insuficiente, segundo elas, já que a procura de tais produtos também diminuiu ao longo dos anos, como pode ser observado na fala da informante 1.

"Ah minha "fia", muitos raizeiros já desistiram de vender, porque a taxa que a prefeitura cobra da gente aqui na feira é muito cara e a gente também tem vendido pouco ultimamente". (Informante 1).

Outro fator que pode ter contribuído para a diminuição do número de vendedores de plantas medicinais foi a reestruturação da feira de Arapiraca, ocorrida a partir de 2004 quando deixa de existir a feira tradicional, que era única e ocorria às segundas-feiras ocupando às ruas do centro da cidade, onde eram comercializados os mais diferentes produtos, e nestas havia também a figura dos meizinheiros ou mangaeiros, como eram conhecidos os que trabalhavam com raízes para tratar alguma doença. Adotando nova configuração, foi dividida em diversas feiras espalhadas pelos bairros da cidade, como mostrado na tabela

Rev. Bras. PI. Med., Campinas, v.18, n.2, p.462-472, 2016. 
1, ocorrendo em dias diferentes da semana. $\mathrm{O}$ desenvolvimento do comércio formal com o crescimento das denominadas lojas de produtos naturais que vendem plantas medicinais de acordo com as determinações da ANVISA, seguindo padrões de higiene e qualidade, também pode ter contribuído para a diminuição da procura de plantas medicinais nas feiras livres de Arapiraca.

\section{Plantas comercializadas}

Todas as plantas comercializadas são compradas de terceiros. Nenhum comerciante afirmou cultivar as plantas que vendia. As plantas são provenientes de outras cidades e até mesmo de outros estados, como Pernambuco e Sergipe, segundo eles devido à dificuldade em encontrar as plantas na cidade e em regiões próximas. Padrão semelhante foi observado nos estudos de Rocha et al.,(2013), que analisou o comércio de plantas medicinais em Currais Novos, MG e por Alves et al., (2008) estudando o comércio das cidades de Campina Grande/PB, João Pessoa/PB, São Luis/MA, Teresina/PI e Belém/PA, nos quais as plantas comercializadas também são compradas de terceiros.

Os cuidados tomados pelos raizeiros e comerciantes são apenas de lavagem e secagem, visto que a maioria das espécies são obtidas frescas. Afirmaram que embora façam indicações de plantas e preparados das mesmas, muitas pessoas os procuram sabendo que plantas desejam comprar. As plantas mais comercializadas são as indicadas para câncer, próstata, diabetes, inflamação e problemas pulmonares. Alves et al. (2008) também apresentaram resultados semelhantes em sua pesquisa, na qual inflamações, diabetes e gastrite foram as enfermidades que tiveram maior número de indicações para tratamento com as plantas medicinais.

Nas feiras, as plantas são comercializadas ao ar livre, estando propícias à contaminação (Figura 3) e nas casas de ervas, as mesmas são comercializadas em pedaços amarrados em pequenos molhos ou dentro de sacos plásticos lacrados (Figura 4) e em garrafas, para ser acrescentado o vinho ou suco de uva. Além disso, esses produtos são vendidos sem as informações relativas às contraindicações, podendo comprometer assim, a saúde de quem as consumir.

De acordo com o Art. $9^{\circ}$ da Resolução RDC no 10, de 9 de março de 2010 da ANVISA, a embalagem deve garantir a proteção da droga vegetal contra contaminações e efeitos da luz e umidade e apresentar lacre ou selo de segurança que garanta a inviolabilidade do produto. Apesar de não se enquadrar aos padrões estabelecidos pela ANVISA, o comércio de plantas medicinais nas feiras livres de Arapiraca - AL apresenta um padrão local de comercialização, não havendo, porém, um padrão mínimo de qualidade, os entrevistados seguem a mesma forma de comercialização, tanto na aquisição de matéria prima, como indicação de uso e na disposição destes produtos para venda, indicando assim um padrão de comercialização destas plantas.

Os preparados feitos dessas plantas medicinais são chás, lambedores e garrafadas, e são dispostos para comercialização como mostrado na figura 2.

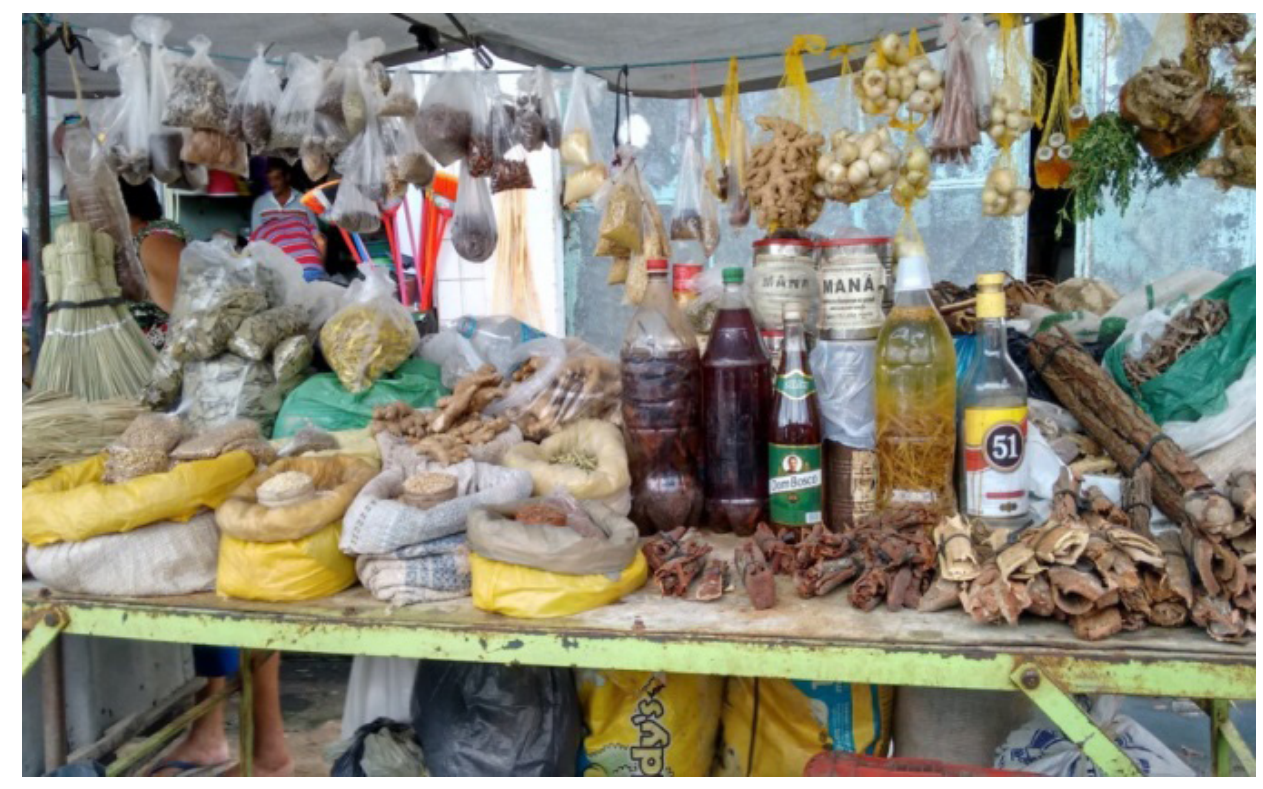

FIGURA 2. Embalagem e forma de oferta de plantas medicinais em feiras livres de Arapiraca-AL Fonte: Dados da pesquisa. 


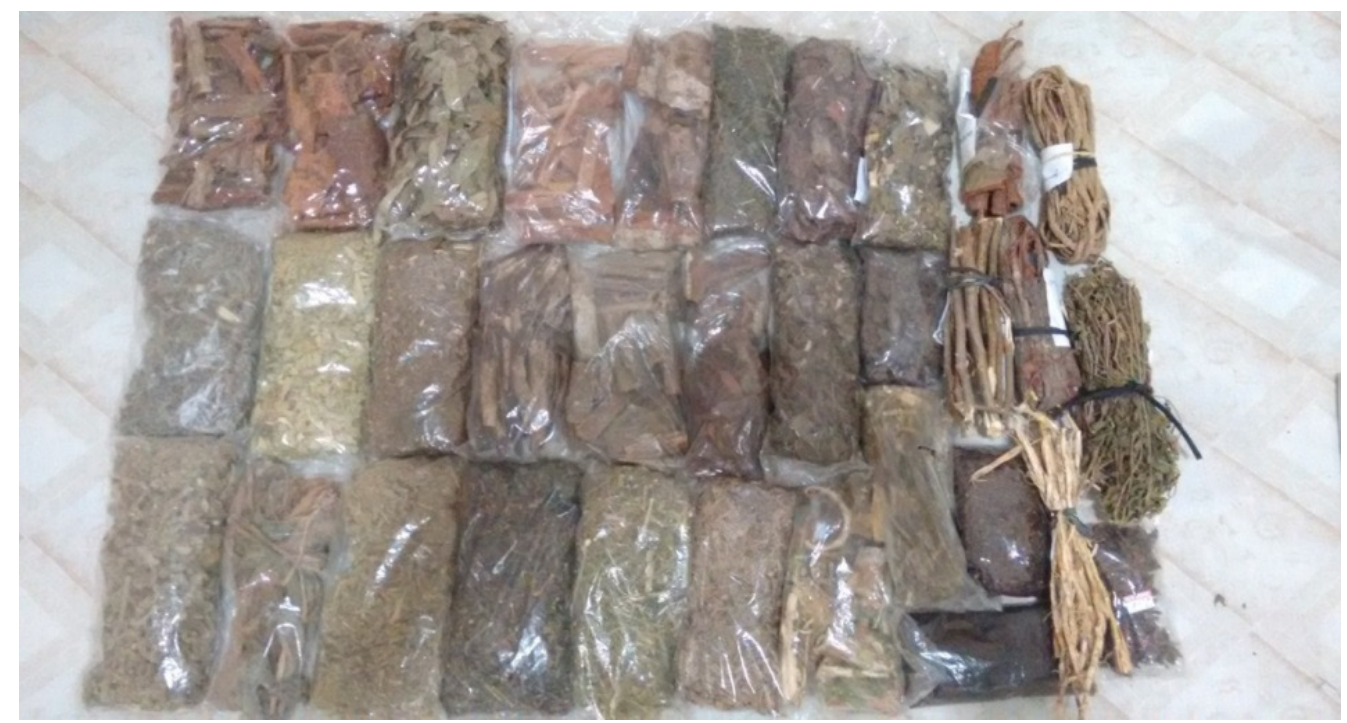

FIGURA 3. Embalagem e forma de oferta de plantas medicinais no comércio de Arapiraca-AL Fonte: Dados da pesquisa

\section{Espécies medicinais}

Foram citadas pelos entrevistados um total de 42 plantas medicinais, destas, 14 não foram identificadas. A tabela 2 destaca estas espécies, bem como as indicações, origem e as formas de uso informadas pelos entrevistados. Apesar de poucos informantes, pode-se observar a riqueza do conhecimento dos mesmos e a variedade de espécies, comercializadas na zona urbana do município.

Do total de espécies identificadas, a maior parte ( $82 \%)$ é nativa, sendo o hábito predominante o arbóreo. As espécies sabugueiro (Sambucus australis Cham. \& Schltdl), erva-doce (Pimpinella anisum L.), espinheira-santa (Maytenus ilicifolia Mart. ex Reissek ), boldo (Peumus boldus Molina), quebra-pedra (Phyllanthus niruri L.) e capim santo (Cymbopogon citratus (DC.) Stapf ) constam na Farmacopeia Brasileira, possuindo informações semelhantes em relação às partes utilizadas citadas pelos informantes.

A Fabaceae destacou-se como tendo o maior número de espécies citadas, resultado semelhante ao obtido por Lós (2011) em estudo realizado nas feiras livres do mesmo município.

O comércio de plantas medicinais tem grande importância social e econômica, uma vez que a utilização de plantas medicinais apresenta uma melhor relação custo/benefício quando comparada aos produtos sintéticos, pois sua ação biológica é eficaz com baixa toxicidade e efeitos colaterais, além de apresentar um custo de produção inferior e, consequentemente, um preço de venda menor. Soma-se a estes dados o fato de que $80 \%$ da população mundial utilizam estas plantas ou preparações destas no que se refere à atenção primária de saúde (Fuzér \& Souza, 2003; Brasil, 2006).

Souza et al., (2012) estudando a comercialização de plantas medicinais no Mercado Central de Belo Horizonte destaca que há carência de comunicação efetiva entre os canais de distribuição e produção, recomendando a construção de uma rede eficiente de divulgação das plantas medicinais, o que poderia ser estabelecido por políticas de comunicação integradas ao Programa de Desenvolvimento de Plantas Medicinais.

Nesse sentido a implantação da fitoterapia no Sistema Único de Saúde através das Práticas Integrativas e Complementares, cuja diretriz PMF 5 destaca o "fortalecimento e ampliação da participação popular e do controle social" (Brasil, 2006b) vem despertando interesse popular e institucional, já que possibilita a abertura do conhecimento das plantas medicinais brasileiras e seu correto emprego como forma de manutenção e recuperação da saúde (Bruning, 2015) sendo uma oportunidade de fusão entre os saberes popular e o científico, que possa incorporar o conhecimento tradicional sobre plantas medicinais de raizeiros e comerciantes de ervas, capacitá-los para o correto manejo e comercialização destas espécies e para adoção de rotinas de Boas Práticas em seus locais de comércio, oferecendo oportunidades de geração de renda para esses comerciantes, preservando-se dessa forma a comercialização de plantas medicinais em feiras livres, e o saber popular a elas associado, sendo um forte argumento para a conservação da biodiversidade. 
TABELA 2. Lista de plantas medicinais citadas pelos participantes da pesquisa. $O R=$ origem; $N A=$ nativa; $E X=$ exótica; $A R=$ arbusto; $S A=$ subarbusto; $M A C$ = Número de registro (Herbário MAC/IMA-AL). ENI = Espécie não identificada por Herbário

\begin{tabular}{|c|c|c|c|c|c|c|}
\hline $\begin{array}{l}\text { Família / Nome } \\
\text { Científico }\end{array}$ & Nome popular & Indicação de uso & OR & Hábito & $\begin{array}{l}\text { Formas de } \\
\text { uso }\end{array}$ & Parte usada \\
\hline \multicolumn{7}{|l|}{ ADOXACEAE } \\
\hline $\begin{array}{l}\text { Sambucus australis } \\
\text { Cham. \& Schltdl (MAC } \\
\text { 46274) }\end{array}$ & Sabugueiro & Tosse, Gripe, Febre & NA & AR & Chá & Flor, fruto \\
\hline \multicolumn{7}{|l|}{ AMARANTHACEAE } \\
\hline $\begin{array}{l}\text { Chenopodium } \\
\text { ambrosioides L. (MAC } \\
\text { 46258) }\end{array}$ & Mastruz & $\begin{array}{l}\text { Febre, Tosse, Gripe, Dor de cabeça, Verme, } \\
\text { Cansaço, Dor de barriga, Infecção intestinal, } \\
\text { Ânsia de vômito, Fraqueza, Pneumonia, } \\
\text { Inflamação vaginal, Hemorróidas }\end{array}$ & NA & Erva & $\begin{array}{l}\text { Chá, } \\
\text { Lambedor }\end{array}$ & Folha, raiz \\
\hline \multicolumn{7}{|l|}{ ANACARDIACEAE } \\
\hline $\begin{array}{l}\text { Schinus terebinthifolius } \\
\text { Raddi (MAC 46273) }\end{array}$ & Aroeira & $\begin{array}{l}\text { Inflamação, Gastrite, Infecção, Mioma, } \\
\text { Cicatrização, Inflamação no útero, Descontrole } \\
\text { na menstruação }\end{array}$ & NA & Árvore & $\begin{array}{l}\text { Chá, Banho } \\
\text { de assento }\end{array}$ & $\begin{array}{l}\text { Casca, } \\
\text { folhas }\end{array}$ \\
\hline \multicolumn{7}{|l|}{ APIACEAE } \\
\hline $\begin{array}{l}\text { Pimpinella anisum L. } \\
\text { (MAC 54399) }\end{array}$ & Erva-doce & $\begin{array}{l}\text { Calmante, Mal estar, Barriga inchada, Intestino } \\
\text { preso, Pressão alta, Ansiedade, Insônia, Cólica, } \\
\text { Dor de barriga }\end{array}$ & EX & Erva & Chá & $\begin{array}{l}\text { Folhas, } \\
\text { semente }\end{array}$ \\
\hline \multicolumn{7}{|l|}{ ASTERACEAE } \\
\hline $\begin{array}{l}\text { Artemisia absinthium L. } \\
\text { (MAC 46284) }\end{array}$ & Loma, Losna & Cólica, Aborto, Diarreia & NA & SA & Chá & Folhas \\
\hline \multicolumn{7}{|l|}{ BIGNONIACEAE } \\
\hline $\begin{array}{l}\text { Handroanthus } \\
\text { impetiginosus (Mart. ex } \\
\text { DC.) Mattos (ENI) }\end{array}$ & Pau d'arco & $\begin{array}{l}\text { Coração, Rins, Dor de Cabeça, Inflamação, } \\
\text { Diabetes, Pedra nos rins }\end{array}$ & NA & Árvore & Chá & $\begin{array}{l}\text { Casca, } \\
\text { folhas }\end{array}$ \\
\hline \multicolumn{7}{|l|}{ BORAGINACEAE } \\
\hline $\begin{array}{l}\text { Symphytum officinale } \\
\text { L. (ENI) }\end{array}$ & Confrei & Pressão alta, Dor, Inflamação & EX & Erva & Chá & Folhas \\
\hline \multicolumn{7}{|l|}{ CELASTRACEAE } \\
\hline $\begin{array}{l}\text { Maytenus rigida Mart. } \\
\text { (MAC 46354) }\end{array}$ & Bom nome & Reumatismo, Barriga inchada, & NA & Árvore & $\begin{array}{l}\text { Chá, } \\
\text { Garrafada }\end{array}$ & Casca \\
\hline $\begin{array}{l}\text { Maytenus ilicifolia Mart. } \\
\text { ex Reissek (MAC } \\
\text { 37056) }\end{array}$ & $\begin{array}{l}\text { Espinheira- } \\
\text { santa }\end{array}$ & Circulação, Inflamação & NA & Árvore & Chá & Folha, raiz \\
\hline \multicolumn{7}{|l|}{ CRASSULACEAE } \\
\hline $\begin{array}{l}\text { Bryophyllum calycinum } \\
\text { Salisb. (MAC 46256) }\end{array}$ & Pra tudo & $\begin{array}{l}\text { Dor de barriga, Garganta inflamada, Tumor, } \\
\text { Dor de cabeça, Dor no corpo, Tosse, Catarro, } \\
\text { Inflamação, Verme, Gastrite, Dor no ouvido, Dor } \\
\text { nas articulações. }\end{array}$ & NA & Erva & Chá & Folha \\
\hline \multicolumn{7}{|l|}{ FABACEAE } \\
\hline $\begin{array}{l}\text { Libidibia ferrea (Mart. } \\
\text { ex Tul.) L.P.Queiroz } \\
\text { (ENI) }\end{array}$ & Juncá, Junça & Reumatismo, Diabetes & NA & Árvore & $\begin{array}{l}\text { Chá, } \\
\text { garrafada }\end{array}$ & Casca, raiz \\
\hline $\begin{array}{l}\text { Bauhinia cheilantha } \\
\text { (Bong.) Steud. (ENI) }\end{array}$ & Pata de vaca & Sangue grosso, Diabetes, Pedra nos rins & NA & Árvore & Chá & Casca, folha \\
\hline $\begin{array}{l}\text { Caesalpinia ferrea } \\
\text { Mart. ex Tul. var. férrea } \\
\text { (MAC 36213) }\end{array}$ & Pau ferro & Reumatismo, Inflamação & NA & Árvore & Garrafada & Casca \\
\hline $\begin{array}{l}\text { Caesalpinia } \\
\text { pyramidalis L.(MAC } \\
54390 \text { ) }\end{array}$ & Catingueira & Dor nos ossos, Fraqueza, Estimulante sexual & NA & Árvore & $\begin{array}{l}\text { Chá, } \\
\text { Garrafada }\end{array}$ & Folha, raiz \\
\hline $\begin{array}{l}\text { Abarema cochliacarpos } \\
\text { (Gomes) Barneby \& } \\
\text { J.W.Grimes (MAC } \\
54483 \text { ) }\end{array}$ & Barbatimão & $\begin{array}{l}\text { Circulação, Inflamação, Gastrite, Câncer, } \\
\text { Infecção, Inflamação vaginal, Inflamação nos } \\
\text { dentes, Tumor, Inflamação no útero, Infecção } \\
\text { urinária, Infecção intestinal, Pedra nos rins, } \\
\text { Inflamação no útero, Reumatismo, Mioma. }\end{array}$ & NA & Árvore & $\begin{array}{l}\text { Chá, } \\
\text { Garrafada, } \\
\text { Lambedor }\end{array}$ & $\begin{array}{l}\text { Casca, } \\
\text { Folha, } \\
\text { Entrecasca }\end{array}$ \\
\hline
\end{tabular}


TABELA 2. Lista de plantas medicinais citadas pelos participantes da pesquisa. $O R=$ origem; $N A=$ nativa; $E X=$ exótica; $\mathrm{AR}=$ arbusto; $\mathrm{SA}=$ subarbusto; $\mathrm{MAC}$ = Número de registro (Herbário MAC/IMA-AL). ENI = Espécie não identificada por Herbário

\begin{tabular}{|c|c|c|c|c|c|c|}
\hline $\begin{array}{l}\text { Anadenanthera } \\
\text { colubrina (Vell.) Brenan } \\
\text { (MAC } 54496\end{array}$ & Angico & $\begin{array}{l}\text { Inflamação, Ferimento, Infecção urinária, } \\
\text { Infecção pulmonar }\end{array}$ & NA & Árvore & $\begin{array}{l}\text { Chá, } \\
\text { Garrafada, } \\
\text { Lambedor }\end{array}$ & Casca \\
\hline \multicolumn{7}{|l|}{ LAMIACEAE } \\
\hline $\begin{array}{l}\text { Mentha } x \text { vilosa Huds. } \\
\text { (MAC 54480) }\end{array}$ & $\begin{array}{l}\text { Hortelã da } \\
\text { folha pequena / } \\
\text { miúda }\end{array}$ & $\begin{array}{l}\text { Tosse, Cólica, Dor de cabeça, Dor de barriga, } \\
\text { Diarreia, Pressão alta, Gripe, Ânsia de vômito, } \\
\text { Dor, Menstruação atrasada, Verme, Mal estar, } \\
\text { Azia }\end{array}$ & EX & Erva & $\begin{array}{l}\text { Chá, } \\
\text { Lambedor }\end{array}$ & Folha \\
\hline \multicolumn{7}{|l|}{ MONIMIACEAE } \\
\hline $\begin{array}{l}\text { Peumus boldus Molina } \\
\text { (ENI) }\end{array}$ & Boldo & $\begin{array}{l}\text { Má digestão, Gases, Dor abdominal, Diarreia, } \\
\text { Dor de barriga, Dor, Mal estar, Barriga inchada }\end{array}$ & EX & SA & Chá & Folha \\
\hline \multicolumn{7}{|l|}{ MYRTACEAE } \\
\hline $\begin{array}{l}\text { Eucalyptus sp. (MAC } \\
54388)\end{array}$ & Eucalipto & $\begin{array}{l}\text { Febre, Gripe, Garganta inflamada, Gases, } \\
\text { Tosse }\end{array}$ & -- & Árvore & Chá, Banho & Folha \\
\hline \multicolumn{7}{|l|}{ PHYLLANTHACEAE } \\
\hline $\begin{array}{l}\text { Phyllanthus niruri L. } \\
\text { (MAC 46278) }\end{array}$ & Quebra-pedra & $\begin{array}{l}\text { Menstruação atrasada, Rins, Inflamação nos } \\
\text { rins }\end{array}$ & NA & Erva & $\begin{array}{l}\text { Chá, } \\
\text { Garrafada }\end{array}$ & Folha, raiz \\
\hline \multicolumn{7}{|l|}{ POACEAE } \\
\hline $\begin{array}{l}\text { Cymbopogon citratus } \\
\text { (DC.) Stapf (ENI) }\end{array}$ & Capim-santo & $\begin{array}{l}\text { Gripe, Gases, Dor abdominal, Gastrite, } \\
\text { Calmante, Dor no fígado, Dor de cabeça, } \\
\text { Barriga inchada }\end{array}$ & NA & Erva & Chá & Folha \\
\hline $\begin{array}{l}\text { Imperata brasiliensis } \\
\text { Trin. (ENI) }\end{array}$ & Sapé & $\begin{array}{l}\text { Inflamação na gengiva, Nascimento dos dentes } \\
\text { de leite }\end{array}$ & NA & Erva & Chá & Raiz \\
\hline \multicolumn{7}{|l|}{ ROSACEAE } \\
\hline $\begin{array}{l}\text { Rubus sellowii Cham. } \\
\text { \& Schltdl. (ENI) }\end{array}$ & Amora & Gastrite, Menopausa & NA & $A R$ & $\begin{array}{c}\text { Chá, } \\
\text { Garrafada }\end{array}$ & Folha, fruto \\
\hline \multicolumn{7}{|l|}{ RUBIACEAE } \\
\hline $\begin{array}{l}\text { Carapichea } \\
\text { ipecacuanha (Brot.) L. } \\
\text { Andersson (ENI) }\end{array}$ & Papaconha & Gripe, Ferimento & NA & Erva & Chá & Folha, raiz \\
\hline $\begin{array}{l}\text { Coutarea hexandra } \\
\text { (Jacq.) K. Schum. } \\
\text { (ENI) }\end{array}$ & Quina-quina & Anemia, Diabetes, Aborto & NA & Árvore & Chá & Casca \\
\hline \multicolumn{7}{|l|}{ RUTACEAE } \\
\hline $\begin{array}{l}\text { Ruta graveolens L. } \\
\text { (MAC 46259) }\end{array}$ & Arruda & $\begin{array}{l}\text { Cólica, Dor de ouvido, Gripe, Febre, Inflamação } \\
\text { no ouvido, Sinusite, Dor de cabeça, Dor, Dores } \\
\text { musculares, Limpeza intima }\end{array}$ & EX & SA & $\begin{array}{l}\text { Chá, Sumo, } \\
\text { Banho }\end{array}$ & Folha \\
\hline \multicolumn{7}{|l|}{ SAPOTACEAE } \\
\hline $\begin{array}{l}\text { Sideroxylon } \\
\text { obtusifolium (Roem. } \\
\text { \& Schult.) T. D. Penn. } \\
\text { (ENI) }\end{array}$ & Quixabeira & Dor na coluna, Cicatrização, Infecção & NA & Árvore & $\begin{array}{l}\text { Chá, } \\
\text { Garrafada }\end{array}$ & Casca \\
\hline \multicolumn{7}{|l|}{ VERBENACEAE } \\
\hline $\begin{array}{l}\text { Lippia alba (Mill.) N. E. } \\
\text { Br.(MAC 54494) }\end{array}$ & Erva-cidreira & $\begin{array}{l}\text { Gripe, Calmante, Má digestão, Diarreia, Insônia, } \\
\text { Ânsia de vômito, Intestino preso, Nervosismo, } \\
\text { Ansiedade, Mal estar, Barriga inchada, Dor de } \\
\text { cabeça, Pressão alta, Dor de barriga }\end{array}$ & NA & Erva & Chá & Folha \\
\hline \multicolumn{7}{|l|}{ NÃO IDENTIFICADAS } \\
\hline Não identificada 1 & Mijo de ovelha & Inflamação vaginal, Inflamação no reto, Infecção & - & - & Chá & Folha \\
\hline Não identificada 2 & Cavalinha & Calculo na vesícula, rins, circulação e artrite. & _- & _- & Chá & Caule \\
\hline Não identificada 3 & Copaíba & Próstata & - & - & Garrafada & Casca \\
\hline Não identificada 4 & Chá preto & Emagrecer & - & - & Chá & Folhas \\
\hline Não identificada 5 & Chá verde & Colesterol, Emagrecer & - & - & Chá & Folhas \\
\hline Não identificada 6 & Jatobá & Próstata & - & - & Garrafada & Casca \\
\hline Não identificada 7 & Jarrinha & Fluxo menstrual & - & - & Chá & Caule e raiz \\
\hline Não identificada 8 & Mororó & Diabetes, Anemia & - & - & Chá & Casca \\
\hline
\end{tabular}


TABELA 2. Lista de plantas medicinais citadas pelos participantes da pesquisa. $O R=$ origem; $N A=$ nativa; $E X=$ exótica; $A R=$ arbusto; $S A=$ subarbusto; $M A C=$ Número de registro (Herbário MAC/IMA-AL). ENI = Espécie não identificada por Herbário

\begin{tabular}{llllcc}
\hline Não identificada 9 & Porangaba & Colesterol, Diabetes & $\ldots$ & Chá & Folhas \\
\hline Não identificada 10 & Unha de gato & Mioma, Cisto & $\ldots$ & Chá & Casca, folha \\
\hline Não identificada 11 & Sene & Fluxo menstrual & $\ldots$ & Chá & Folhas \\
\hline Não identificada 12 & Anis estrelado & Cólica,Inflamação & Chá & Fruto \\
\hline Não identificada 13 & Carqueja & $\begin{array}{l}\text { Diarréia, Dor de cabeça, Diabetes, Gastrite, } \\
\text { Enxaqueca }\end{array}$ & $\ldots$ & \multirow{2}{*}{ Chá } & Folhas \\
\hline Não identificada 14 & Sucupira & Coluna & $\ldots$ & $\ldots$ & Chá \\
\hline
\end{tabular}

\section{CONCLUSÃO}

O comércio de plantas medicinais nas feiras livres do município de Arapiraca-AL é feito por reduzido número de comerciantes que apresentam padrão local para a aquisição e comercialização dessas plantas, porém não há padrão mínimo de qualidade, sendo necessária a implantação de políticas públicas para a capacitação destes profissionais, agregando valor ao saber popular sobre plantas medicinais.

\section{REFERÊNCIAS}

AFEIRA LIVRE DE ARAPIRACA. Arapiraca legal: voltado ao cidadão arapiraquense. 2011. Disponível em: https:// arapiracalegal.wordpress.com/2011/09/03/feira-dearapiraca. Acessado em: 10 mar. 2016.

ALBUQUERQUE, U. P. Etnobotânica aplicada à conservação da biodiversidade. In: Métodos e técnicas na pesquisa etnobiológica e etnoecológica. (Org.) Albuquerque, U. P.; Lucena, R. F. P.; Cunha, L. V. F. C. $3^{a}$ edição. Nuppeea, 2010. P. 1-559.

ALVES, R. R. N. et al. Aspectos socioeconômicos do comércio de plantas e animais medicinais em áreas metropolitanas do Norte e Nordeste do Brasil. Revista de Biologia e Ciências da Terra, v.8, n.1, p. 181-189, 2008.

AGROLINK. Normas para Produção, Comercialização e Utilização de Sementes. 2015. p. 1-86. Disponível em: <http://www.agrolink.com.br/culturas/soja/arquivos/ anexo.pdf>. Acesso em: 11 marc. 2016.

ARAÚJO, C. A. SILVA, D. M. Plantas utilizadas contra úlcera gástrica no povoado Vila Capim Arapiracaal: um estudo etnobotânico e etnofarmacológico.. 2012 61f. Monografia (Ciências Biológicas). UNEAL Universidade Estadual de Alagoas. Arapiraca-AL.

ARAÚJO, A.C. et al. Caracterização socioeconômicocultural de raizeiros e procedimentos pós-colheita de plantas medicinais comercializadas em Maceió, AL. Revista Brasileira de Plantas Medicinais., v. 11, n. 1, p. 81-91, 2009.

BAILEY, K. Methods of social research. New York: The Free Press, 4ed. 1994. 595p.

BARROS, G. S. C.; Economia da Comercialização Agrícola. Universidade de São Paulo - USP. Escola Superior de Agricultura "Luiz de Queiroz" - ESALQ. Piracicaba. 2007. 221p.

BRASIL. Ministério da Saúde. Política Nacional de
Práticas Integrativas e Complementares no SUS PNPIC-SUS. Brasília: Ministério da Saúde, 2006a. 96p. BRASIL. Ministério da Saúde. A fitoterapia no SUS e - Programa de Pesquisa de Plantas Medicinais da Central de Medicamentos. Brasília: Ministério da Saúde, 2006b. 148p.

BRASIL. Ministério da Saúde. Conselho Nacional de Saúde. Resolução 466 de 12 de dezembro de 2012. Disponível em: http://conselho.saude.gov.br/ resolucoes/2012/Reso466.pdf. Acesso em: 10 mar. 2016

BRUNING, M. C. R. et al. A utilização da fitoterapia e de plantas medicinais em unidades básicas de saúde nos municípios de Cascavel e Foz do Iguaçu Paraná: a visão dos profissionais de saúde. Associação Brasileira de Pós-Graduação em Saúde Coletiva. Novas Edições Acadêmicas, 2015. 12p.

CARVALHO, L. M.; et al. Qualidade em plantas medicinais. Edição 1. Embrapa Tabuleiros Costeiros. Aracaju, SE, 2010. 56p.

ELISABETSKY, E. Etnofarmacologia de algumas tribos brasileiras. In: Suma Etnológica Brasileira. Edição atualizada do Handbook of South American Indians - Etnobiologia V.1, 2 edição. Darcy Ribeiro (Editor et alii). RIBEIRO, Berta (coord.), Petrópolis, Brasil, FINEP/ Vozes, 1997: 135-148.

ANVISA. Agência Nacional de Vigilância Sanitária. Farmacopeia Brasileira, Brasília: 2010. v.2. 904p.,

FENNELL, C. W. etal. Assessing African medicinal plants for efficacy and safety: pharmacological screening and toxicology. Journal of Ethnopharmacology, Limerick, v. 94, p. 205-217, 2004.

FUZÉR, L.; SOUZA, I. IBAMA dá início a núcleo de plantas medicinais. Bionotícias, Rio de Janeiro, n. 57, p.6-7, 2003.

IBGE - Instituto Brasileiro de Geografia e Estatísticas. (2010). Censo Brasileiro. Disponível em:<http://www. censo2010.ibge.gov.br/dados_divulgados>. Acesso em: 30 mar. 2014.

LORENZI, H. Manual de identificação e controle das plantas daninhas. São Paulo: Instituto Plantarum. 6. Ed. 2006. 338 p.

LORENZI, H.; MATOS, F. J. A. Plantas medicinais no Brasil: nativas e exóticas. 2. Ed. Nova Odessa - SP: Instituto Plantarum, 2008. 540 p.

LORENZI, H. Árvores Brasileiras. 4. Ed. v.1. Nova Odessa - SP: Instituto Plantarum, 2002. 384 p.

LÓS, D. W. S. Estudos etnobotânicos sobre plantas medicinais comercializadas em feiras livres no município de Arapiraca-AL. 2011. 53p. Monografia 
(Ciências Biológicas). Universidade Estadual de Alagoas. Arapiraca, AL.

MAIA, C. E. S.; COELHO, T. O. O comércio varejista periódico no espaço urbano no contemporâneo: um estudo na feira hippie de Goiânia. Boletim Goiano de Geografia. Goiânia, v. 17 n.02 , Goiânia: UFG, 1997.

MAXWELL, J. A. Qualitative research design: An interactive approach, 2.ed. Thousand Oaks, CA: Sage. 2005.

MELO, J. G.; et al., Qualidade de produtos a base de plantas medicinais comercializados no Brasil: castanhada-índia (Aesculus hippocastanum L.), capim-limão (Cymbopogon citratus (DC.) Stapf) e centela (Centella asiatica (L.) Urban). Acta Botanica Brasilica. v. 21, no.1, 2007.

MELO, E. C.; et al., Influência do processo de secagem na qualidade de plantas medicinais - Revisão. Engenharia na Agricultura, v. 12, n. 4, p. 307-315, 2004.

MENGUES, S. S; et al., Uso de plantas medicinais na gravidez. Revista Brasileira de Farmacognosia. V. 11, n.1, p. 21-35, 2011.

OLIVEIRA, A. C. S.; PEREIRA, L. S. Importância de plantas medicinais indicadas por especialistas locais na região agreste do Estado de Alagoas (Nordeste do Brasil), 2012. 64p. Monografia (Ciências Biológicas). Universidade Estadual de Alagoas. Arapiraca-AL.

OLIVEIRA NETO, A. P. F. et al. Estudo das garrafadas comercializadas por raizeiros em feiras livres de Arapiraca-Al. 65a Reunião Anual da SBPC. 2013. Disponível em: <http://www.sbpcnet.org.br/livro/65ra/ resumos/resumos/2851.htm>. Acesso em: 25 mar. 2015.

OMS, Organização Mundial De Saúde. (2008b) Traditional medicine: definitions. Disponível em: <http://www.who. int/medicines/areas/traditional/definitions/en/>. Acesso em: 17 mar. 2015.

ARAPIRACA (Cidade). Secretaria de Indústria, comércio e serviço.Feiras livres de Arapiraca. Disponível em:< http://www.arapiraca.al.gov.br/v3/semics.php>. Acesso em: 07 mar. 2016.

ROCHA et al. Características Socioeconômicas dos Comerciantes de Plantas Medicinais De Currais Novos/RN. Revista Holos, ano 29, v.4, 2013.p. 87-100.

SILVA, S. R. et al. Plantas medicinais do Brasil: aspectos gerais sobre legislação e comércio. Brasília, DF: Ministério de Cooperação Econômica e Desenvolvimento da Alemanha e IBAMA. 2001.

SOUZA, M. R. M. et al. Comercialização de plantas medicinais no contexto da cadeia produtiva em Minas Gerais. Revista Brasileira de Plantas Medicinais, v.14, n. esp., p.242-245, 2012.

TRESVENZOL, L. M et al. Estudo sobre o comércio informal de plantas medicinais em Goiânia e cidades vizinhas. Revista Eletrônica de Farmácia. v. 3, n. 1, p. 23-28, 2006. 